\title{
Oriented physical exercise and sports nutrition and the risk of growth of tumours
}

\author{
Bruno Tratz ${ }^{1}$, Guilherme Barroso Langoni de Freitas ${ }^{2,3, *}$ \\ ${ }^{1}$ Personal Trainer and Fitness Coach, State University of Center-West, Guarapuava, Brazil \\ ${ }^{2}$ Department of Pharmacy, State University of Center-West, Guarapuava, Brazil \\ ${ }^{3}$ Post-Degree Program in Internal Medicine and Health Sciences at UFPR, Department of Clinical Patology, Federal University of Parana, \\ Curitiba, Parana, Brazil
}

Email address:

contato.btpersonal@gmail.com (B. Tratz),prof.gbarroso@yahoo.com.br (G. B. L. de Freitas)

\section{To cite this article:}

Bruno Tratz, Guilherme Barroso Langoni de Freitas. Oriented Physical Exercise and Sports Nutrition and the Risk of Growth of Tumours. Cancer Research Journal. Special Issue: Lifestyle and Cancer Risk. Vol. 2, No. 6-1, 2014, pp. 57-63.

doi: $10.11648 /$ j.crj.s.2014020601.17

\begin{abstract}
The health and life quality of men can be preserved and improved using a regular practice of physical activities. It is well known that when properly oriented, the physical exercise can combat several diseases, e. g. cardiovascular, metabolic and even physiological, such as depression. However, the higher oxygen consumption, as well as the activation of specific metabolic pathways during and after the exercises results in the formation of free radicals. Exhausting physical exercises of high intensity elevate the risk of diseases, like pulmonary emphysemas, inflammation, aging and increased risk of damage in the DNA with consequent carcinogenesis. The excessive elevation of free radicals without the optimal accompaniment of antioxidants induces a psychopathological stage known as oxidative stress, which generates lipids, damages to proteins and to the DNA, becoming cytotoxic or causing changes in the cellular functions and even in the tissues. This is a common occurrence in drug users, overexposure to environmental factors such as sun light, metabolic alterations originated from obesity or diabetes, and even physical exercises. There is general agreement that physical training and adequate alimentation, besides protecting against some types of cancer, increases the aspects of anti-tumor immunity and reduces inflammatory mediators. Evidences suggest that the prophylactic effect of the exercise can be attributed to the anti-inflammatory effects mediated by the regular practice of exercises, through the reduction of visceral fat and increase of anti-inflammatory cytokines in the circulation. This study had as objective to demonstrate the importance of a well targeted training, for the performance of physical activities in an adequate intensity associated to antioxidant supplementation, in order to prevent excessive physical wear and appearing of oxidative stress.
\end{abstract}

Keywords: Physical Activity, Oxidative Stress, Overtraining, Antioxidants

\section{Introduction}

The health and life quality of men can be preserved and improved using a regular practice of physical activities [1]. The absence of daily activities generates a sedentary lifestyle, determinant factor in the appearing of pathologies, increasing the risk of mortality and morbidity [1]. It is known that regular and oriented practice of physical exercises can combat several clinical conditions, such as cardiovascular diseases [2], obesity [3], type 2 diabetes [4], osteoporosis and osteoarthrosis [5], leukemia [6], colon [7], breast [8], prostate [9] and lung [10] cancers, besides combating anxiety and depression [1].
On the other hand, excessive exercises of high intensity and poor periodicity of the same can generate an uncontrolled physiological situation, thus developing a factor known as overtraining [11]. During and soon after an exhausting training session occurs a catabolic phase, with reduction of the tolerance to efforts, characterized by reversible alterations of biochemical, hormonal and immunological parameters [12]. Overtraining can occur both in aerobic and anaerobic activities [13].

The higher consumption of oxygen, as well as the activation of specific metabolic pathways during and after 
exercises results in the formation of substances called free radicals [14]. These molecules increase in exhausting and high intensity exercises and were related to a great number of diseases, such as pulmonary emphysema [15], inflammation, aging [16] and increased risk of damage in the DNA with consequent carcinogenesis [17]. The significant rise in these radicals induces a psychopathological stage known as oxidative stress, which generates lipids, damages to proteins and to the DNA, becoming cytotoxic or causing changes in the cellular functions and even in the tissues.

Hormonal and neuroendocrine alterations were also reported during the practice of physical exercises. Strenuous exercises showed clinical and biochemical alterations in short term and risk of diseases in long term [18]. These alterations can unbalance the plasmatic liberation and concentration of pro-inflammatory cytokines, which were several times related to the control of tumor cells $[19,20]$.

The objective of this study will be to discuss the need of using an appropriate periodicity to define the intensity and care with physical exercises, aiming to preserve the health and life quality of men and women, in addition to citing the role of antioxidant supplementation as anti-tumor protector.

\section{Cancer and Oxidative Stress}

Cancer is defined by the uncontrolled and abnormal growth of cells in the organism, which do not have the capacity of differentiating local cells and show invasive and metastatic capacity [21]. It is considered as a multifactorial disease for not having an only causative factor [22]. Nevertheless, the genetic alterations [23], environmental factors [24], eating habits [25] or even stress situations [26] [physical and psychological] may elevate the risk of formation of malignant tumors and worsen the prognosis of cancer.

The stages of initiation, promotion and progression of carcinogenesis have been frequently related to the oxidative stress in circumstances where the excess of free radicals results in tissue damage or in the production of harmful or toxic compounds to tissues [27]. The oxidative stress is caused by the unbalance between the pro-oxidants and antioxidants systems, so that the first is predominant in the organism [17]. This is a common occurrence in drug users [28], excessive exposition to sunlight [29], metabolic alterations originated from obesity [3] or diabetes [30] and even physical exercises [14].

The oxidative stress is responsible for causing structural damages in the DNA and performs an important role in the development of several diseases, including cancer [30]. The incidence of oxidative stress in the development and progress of more than 100 diseases has been suggested by several scientists. There are many evidences that agree with the idea that the oxidative stress acts as successor of numberless illnesses, logically including alterations at the DNA level [31].

Other examples can be found in the correlation between the process of aging on the human body and the increase of free radicals, due to the drop on oxygen used for the metabolic processes and to the initiation and promotion of cancer and tissue lesions by free radicals [32].

The excessive production of species reactive to oxygen and consequent increase of oxidative stress in the body of patients with cancer can affect the response of the treatment and contribute for the tumor recurrence [33]. Evidences of the participation of oxidative stress in carcinogenesis have led to assumptions that the antioxidant supplements can be used in its prevention.

Antioxidants are important not only for the prevention of oxidative stress, but also can assist in the prevention of cancer. Following this idea, it was performed investigations in order to find evidences about the cancer risk reduction through the intake of antioxidants [35]. A study observed concentration reduction of oxidative stress markers in patients who took antioxidants during the cancer treatment. This result can be related to the patient report, which had increase of the muscle strength, reduced fatigue and better quality of life [36].

Antioxidants act in three defense lines against reactive species of oxygen. The first is the prevention, characterized by the protection against the formation of aggressive substances. The second is the interception, where the antioxidants intercept the free radicals. And the third is the repair that occurs if the first two lines were not totally effective and the destructive products by the reactive species accumulated in the organism [27]. Among the antioxidant benefits, it can be highlighted the capacity of enhance the anticancer drugs, therefore, reducing the dose of these without impairing the therapeutic effect and reducing the collateral effects [37].

\section{Physical Exercise, Antioxidants and Oxidative Stress}

The relation between physical exercise and oxidative stress is directly linked to the intensity and duration of the exercise. Intense physical exercise triggers the oxidative stress, generating decreased performance, muscle fatigue, muscle damage and even overtraining [38], which leads to alterations in the immune system and in the training status of individuals [39].

The physical exercise is associated to the increase of free radicals, due to the elevation of oxygen consumption by the active tissues of the organism [40]. If the action of these free radicals will be beneficial or deleterious for the organism will depend on the antioxidants activity, which are substances that suppress these radicals and their harmful effects [41]. Free radicals are naturally produced by the organism and are often of great use, as in the activation of the immunological system, participation on the detoxification of drugs and in the production of nitric oxide, which is fundamental for relaxing blood vessels [42].

Therefore, it is evident that the formation of free radicals in a natural and homeostatic process of the human body. This observation can be proven by analyzing mitochondrial activity in the production of ATP, which occurs through a process of oxidative phosphorylation and is influenced by the synthesis of key molecules and the response to oxidative stress [43]. The 
mitochondria contain many redox enzymes and there is a natural inefficiency of oxidative phosphorylation, thus generating reactive species of oxygen (ROS) [44]. During the practice of physical exercise there is an increase of the necessity of immediate energy sources [45] (e.g. ATP, carbohydrates), and of reserve (e.g. lipids and proteins) [46]. Consequently, the consumption of ATP increases, inducing a greater activity of the mitochondria [47] with increase, both in the production of free radicals as in the necessity of antioxidants for minimizing possible damage caused by the increase of ROS.

The substances which combat the free radicals can be divided in endogenous [48] and exogenous [33] antioxidants. The endogenous are unquestionably essential, however with production and limited saturable action. They can be divides in 4 classes of antioxidants, i. e. endogenous enzyme; soluble; transition metal captors; nutritional.

Some enzymes, through its intrinsic activities produce free radicals, as for example, xanthine oxidase, cyclooxygenase $(\mathrm{COX})$, lipoxygenase (LOX), nitric oxide synthase and mitochondrial oxidase [49]. On the other hand, the class of enzymatic antioxidants has as main representatives the superoxide dismutases (SOD), catalase and the glutathione peroxidase (GSH-Px) [49]. Keeping the balance between the concentration of these oxidant and antioxidant enzymes is essential to minimize possible cell and tissue damages.

The second class of endogenous antioxidants is represented by the micro and macro soluble molecules. They are mainly found in the plasmatic system and interstitial fluids. The glutathione [50], uric acid [51], albumin [52], haptoglobin [53] and hemopexin [54] are representatives of endogenous antioxidants. However, the increase in the body concentration of these substances, due to the necessity of antioxidant or physiological alterations, causes the appearing of diseases (e.g. gouty arthritis) developed by the accumulation of uric acid [55] or alterations in the pharmacokinetics (bioavailability and half life time, $t 1 / 2$ ), from many substances active by the elevation of circulating albumin [56]. So, it is evident a tenuous line between antioxidant activity and possible pathologies from the elevation of soluble antioxidants.

Other two types of endogenous antioxidants which deserve special attention in combating ROS are the transition metal captors and the nutritional antioxidants. The transition metal captors associate to metals known as pro-oxidants, such as copper and iron $[57,58]$. The main representatives of this class are the transferrin [59], lactoferrin [60], ferritin [61], albumin and ceruloplasmin [62]. However, their concentration is not dependant on the quantity of circulating free radicals, that is, an individual under constant physical activity will have greater production of ROS without the proportional elevation of lactoferrin for example. This turns this protective class only at basal levels, being considered a class with low antioxidant activity when compared to the other 3 classes previously mentioned.

The last but not the least, is the class of nutritional antioxidants. This class is sometimes confused with the exogenous antioxidants, especially because they are also found in food. Some vitamins are known protective agents in the control of free radicals, e. g. ascorbic acid (vitamin C) [63], alpha-tocopherol (vitamin E) [64] and the beta carotene (vitamin A) [65]. They can be obviously obtained from food [66] or simply through supplementation.

It is noteworthy that alimentation in responsible for providing them both, oxidants and antioxidants [67]. Therefore, a dietetic deficiency of antioxidants and of other essential substances can also cause oxidative stress [25]. In order to minimize oxidative effects originated from a deficient nutritional state, it were developed synthetic oxidants, for example the acetylcysteine [68], coenzyme Q10 [69] flavonoids [70], allopurinol [71], probucol [72], vitamins [73], beta carotene [74], selenium and zinc, among others. [75] The correct use and the quantitative physiological control of these substances, make possible for individuals with high production of free radicals, for example, athletes, to do not develop an oxidative stress state. Nevertheless, it is only plausible when there is the accompaniment of habilitated professionals, i. e. nutritionists, pharmacists, doctors and physical trainers.

Besides a good nutrition, a regular practice of moderated physical exercises positively alter the oxidative homeostasis of cells and tissues, due to the decrease of oxidative damage and increase of the resistance to oxidative stress [41]. These are qualitative and quantitative physiological responses of physical preparation improvement. From this, it is aimed as adaptive response to an efficient training. Higher levels of antioxidant defense and low levels of oxidative stress production [76]. For this reason, the scientific community has discussed the application of physical exercises as a non pharmacologic strategy for cancer prevention and rehabilitation of individuals during and after the treatment [77].

\section{Overtraining Risk}

The regular practice of exercises is recommended for improving the health of the individual. The is a consensus that the physical training, besides protecting against some types of cancer, also increases the aspects of anti tumor immunity and reduces the anti inflammatory mediators. Evidences suggest that the prophylactic effect of exercises can be attributed to the anti inflammatory effect mediated by the regular practice of exercises, through reduction of visceral fat and increase of anti inflammatory cytokines in the circulation [78].

On the other hand, the overtraining, excess and high intensity of exercises can harm the immune function [29], cause chronic and acute inflammatory processes [79-81], generate hormonal processes [82], between other harmful effects [83]. In addition to these diseases, physiological alterations are also common in this situation, e. g. depression [84] and apathy [85], which can elevate the state of stress for altering the mood and the sleep. The combination of these factors assists in immunological and biochemical modifications, which include increase of the hormone of stress (corticoid) [86] with subsequent drop of the immunity, 
elevation of glycemia and insulin resistance. Nevertheless, despite of the notably importance of the relation between overtraining and pathological states, there is still a great difficulty by the athlete in identifying it, what increases the necessity of multi professional monitoring.

The cellular immunodeficiency is directly related to several types of cancer (head, neck, lung, esophagus and breast) and evidences point that other tumors are equally associated to cellular immunodeficiency. Leukemia and lymphomas are more frequent in children with immunodeficiency [87].

Adipocytes are cells that perform an endocrine role, producing hormones, cytokines and growth factors. The cytokines are liberated from the precursors of adipocite cells, called preadipocytes. In obesity there is an unbalanced maturation, with higher quantities of preadipocytes, and consequently, a greater secretion of pro inflammatory cytokines. Therefore, the increase in the liberation of pro inflammatory cytokines resulting from obesity is a great factor of risk for the development of breast cancer in women in the post menopause state [88].

A great number of evidences from the observation studies indicate that Type 2 diabetes is associated to the incidence of pancreatic, liver, endometrium, colon, breast, and bladder cancers. However, other potential mechanisms also must be considered: body fat and estrogen production (breast cancer in men and women), body fat and pancreatic inflammation induced by fat (pancreas cancer), visceral fat and hepatic steatosis (liver cancer), metabolic syndrome and resistance to insulin, thus producing mitogenic effect to insulin (all cancers) [30].

The unbalance between production of ROS/RNS and the removal by systems of antioxidant defense is denominated oxidative stress and can be originated from physiological processes, such as acute inflammation [89].

Beyond the concern with overtraining, environmental factors must be also considered. In outdoor sports, the immunosuppression induced by UV may facilitate the initiation and promotion of tumors. Athletes that train and compete in outdoor sports are exposed to UV lights, thus, there is greater risk of developing skin cancer [29].

A revision study about the mortality and longevity of professional athletes showed that they have greater longevity than the average population. This is due the adequate periodicity in training, where it was observed that exercises showed an important role in the prevention of several diseases and types of cancer (colon, breast, and lung) [90]. The cardiorespiratory capacity, improved by aerobic activities, has been associated to reduction of risk of chronic diseases (hypertension, heart disease and type II diabetes). The exercise of resistance for prevention of chronic diseases, in strength athletes, is still not well understood and deserves further study [91].

Another study [92] induced metabolic stress in order to analyze the body capacity in protecting the central nervous system from high and toxic blood ammonia during the chronic and acute exercise, such factor that triggers hepatic insufficiency and alteration of the metabolic states, such as cancer or thermal lesions. The results showed to be satisfactory for the better performance management of athletes.

A cohort study [93] conducted with 2448 professional athletes compared to 1712 adult non athlete men analyzed the effect of physical activities in the incidence of cancer. A smaller incidence was observed in athletes due to the healthy lifestyle and also to the lesser number of smokers. For this reason, despite the high production of free radicals, a healthy lifestyle is able to minimize the risks.

\section{Conclusion}

Basing on the quoted studies, it becomes clear the importance of an individualized well oriented periodicity in training for the performance of physical activities in an adequate intensity, in order to prevent a physical wear enough for the occurrence of excessive oxidative stress. Physical trainers' orientation along with a balanced diet, with the necessary ingestion of antioxidants minimized the risks in pathologies development. Professional athletes or even amateurs must always keep control of biochemical markers in order to reduce the risk of lacking physiological control, which would weaken the immune system, thus elevating the risk of appearing several diseases, including cancer.

\section{References}

[1] Carvalho T, Nobrega A C L, Lazzoli J K, Magni J R T, Rezende L, Drummond F A, Oliveira M A B, De Rose E H, Araujo C G S, Teixeira J A C (1996) Posição oficial da Sociedade Brasileira de Medicina do Esporte: atividade física e saúde. Rev Bras Med Esport 2(4), 79-81.

[2] Agarwal S K (2012) Cardiovascular benefits of exercise. Int J Gen Med 5, 541-5.

[3] Leite N, Milano G E, Cieslak F, Lopes W A, Rodacki A, Radominski R B (2009) Effects of exercise and nutritional guidance on metabolic syndrome in obese adolescent. Rev Bras Fisioter. 13, 73-81.

[4] Albright A, Franz M, Hornsby G, Kriska A, Marrero D, Ullrich I (2000) American college of sports medicine position stand. Exercise and type 2 diabetes. Med Sci Sports Exerc 32, 1345-60.

[5] Kohrt W M, Bloomfield S A, Little K D, Nelson M E, Yingling V R (2004) American College of Sports Medicine. American College of Sports Medicine Position Stand: physical activity and bone health. Med Sci Sports Exerc 36(11), 1985-96.

[6] Battaglini C L, Kackney A C, Garcia R, Groff D, Evans E, Shea $T$ (2009) The effects of an exercise program in leukemia patients. Integr Cancer Ther, Thousand Oaks 8(2), 130-138.

[7] Davies N J, Batehup L, Thomas R (2011) Role of diet and physical activity in cancer survivorship. Brit $\mathrm{J}$ of Cancer 105(S1), S52 - S73.

[8] Cheema B, Gaul C A, Lane K, Singh M A F (2007) Progressive resistance training in breast câncer: a systematic review of clinical trials. Breast Cancer Res and Treat 109(1), 9-26. 
[9] Schneider C, Hsieh C C, Sprod L K, Carter S D, Hayward R (2007) Cancer treatment-induced alternations in muscular fitness and quality of life: the role of exercise training. Ann of Onc, Viganello-Lugano, 18(12), 1957-1962.

[10] Friedenreich C M, Orenstein M R (2002) Physical activity and cancer prevention: etiologic evidence and biological mechanisms. J Nutr 132 (suppl), 3456S-64S.

[11] Baptista C A S, Ghorayeb N, Dioguardi G S (1999) Sobretreinamento. In N. Ghorayeb, T. Barros [ed]. O Exercício. São Paulo: Atheneu, 1999, 313-320.

[12] Silva A S R, Santhiago V, Gobatto C A (2006) Compreendendo o overtraining no desporto: da definição ao tratamento. Rev Port Cien Desp 6(2), 229-238.

[13] Israel S Z (1976) Problematik des übertraings aus internisistischer und leistungs physiologischer sicht. Med Sport $16,1-12$.

[14] Halliwell B, Gutteridge J M C (1999) Free radicals in biology and medicine. 3rd ed. New York: Oxford, 1999.

[15] Southorn P A, Powis G (1988) Free radicals in medicine II. Involvement in human disease. Mayo Clin Proc 63, 390-408.

[16] Meneguini R (1987) A toxicidade do oxigênio. Ciência Hoje 5, 28.

[17] Schneider C D, Oliveira A R (2004) Radicais livres de oxigênio e exercício: mecanismos de formação e adaptação ao treinamento físico. Rev Bras Med Esp 10(4), 308-313.

[18] Mostorakos G, Paylatou M, Diamanti-Kandarakis E G. P (2005) Chrousos. Exercise and the Stress System. Hormones 4(2), 73-89.

[19] Lippitz B E (2013) Cytokine patterns in patients with cancer: a systematic review. Lancet Oncol 14(6), 218-28.

[20] Dranoff G (2004) Cytokins in cancer pathogenesis and cancer therapy. Nat Rev Cancer 4, 11-22.

[21] AMERICAN CANCER SOCIETY (2005) Cancer facts and figures. ACS Publications Disponible on: www.cancer.org.

[22] Hayes S, Spence R R, Galvão D A, Newton R U (2009) Australian Association for Exercise and Sport Science position Stand: Optimizing Cancer outcomes trough Exercise. J of Sci and Med in Sport 12(4), 428-434.

[23] Cho K R, Vogelstein B (1992) Genetic alterations in the adenoma-carcinoma sequence. Cancer 70, 1727-31.

[24] Cesar A C G, Silva A E, Tajara E H (2002) Genetics and environmental factors in gastric carcinogenesis. Arq. Gastroenterol. (4), 253-259.

[25] Halliwell B (2006) Reactive species and antioxidants. Redox biology is a fundamental theme of aerobic life. Plant Physiol. 141(3), 312-22.

[26] Ortiz M S; Willey J F; Chiang J J (2014) How stress gets under the skin o cómo el estrés psicológico se introduce bajo la piel. Rev. Med. Chile 142(6), 767-774.

[27] Rohenkohl C C, Carniel A P, Colpo E (2011) Antioxidants consumption during chemotherapy treatment. ABCD Arq Bras Cir Dig 24(2), 107-112.

[28] Salazar L, Palacio A C, Rodriguez J R (2011) Mechanisms of cardiotoxicity: antineoplastics, nonsteroidal anti-inflammatory drugs, antipsychotics, cocaethylene and sympathomimetics. Rev Colom Cardiol, 18(2), 100-110.

[29] Moehrle M (2008) Outdoor sports and skin cancer. Clinics in Dermatology 26, 12-15.

[30] Joost H G (2014) Diabetes and cancer: Epidemiology and potential mechanisms. Diab Vasc Dis Res. 11(6), 390-394.

[31] Gago-Domínguez M, Jiang X, Castelao J E (2007) Lipid peroxidation, oxidative stress genes and dietary factors in breast cancer protection: a hypothesis. Breast Cancer Res 9, 201-211.

[32] Durand M, Mach N (2013) El ácido alfa lipoico y su poder antioxidante frente al cáncer y las patologias de sensibilización central. Nutr Hosp. 28(4), 1031-1038.

[33] Nunes-Selles A J (2005) Antioxidant Therapy: Myth or Reality? J. Braz. Chem. Soc. 16(4), 699-710.

[34] Rockenbach G, Di Pietro P F, Ambrosi C, Boaventura B C B, Vieira F G K, Crippa C G, Da Silva E L, Fausto M A (2011) Dietary intake and oxidative stress in breast cancer: before and after treatments. Nutr Hosp 26(4), 737-744.

[35] Triana B E G, Bernabeu A S, Garcia L S (2012) Oxidative stress and antioxidants in cancer prevention. Revista Haban de Cien Méd 12(2), 187-196.

[36] Avelar M, Martinez A (2012) Do Casiopeinas ${ }^{\circledR}$ Prevent Cancer Disease by Acting as Antiradicals? A Chemical Reactivity Study Applying Density Functional Theory. J. Mex. Chem. Soc. 56(3), 250-256.

[37] Fuchs-Tarlovsky V, Bejarano-Rosales M, Gutierrez-Salmean G, Casilas M A, Lopez-Alvarenga J C, Ceballos Reyes G M (2011) Efecto de la suplementación con antioxidantes sobre el estrés oxidativo y la calidad de vida durante el tratamiento oncológico en pacientes con cáncer cérvico uterino. Nutr Hosp 26(4), 819-826.

[38] Santos H S, Souza Cruz W M (2001) A Terapia Nutricional com Vitaminas Antioxidantes e o Tratamento Quimioterápico Oncológico. Rev Bras Cancerol 47(3), 303-08.

[39] Konig D, Wagner K H, Elmadfa I, Berg A (2001) Exercise and oxidative stress: significance of antioxidants with reference to inflammatory, muscular, and systemic stress. Exerc Immunol Rev 7, 108-133.

[40] Alessio H M, Hagerman A E, Fulkerson B K, Ambrose J, Rice R E, Wiley R L (2000) Generation of reactive oxygen species after exhaustive aerobic and isometric exercise. Med Sci Sports Exerc 32, 1576-1581.

[41] Cooper C E, Vollaard N B, Choeiri T, Wilson M T (2002) Exercise, free radicals and oxidative stress. Biochem Soc Trans $30,280-285$.

[42] Amorim A G, Tirapegui J (2008) Aspectos atuais da relação entre exercício físico, estresse oxidativo e magnésio. Rev. Nutr. 21(5), 563-575.

[43] Jenkins R R, Goldfarba A (1993) Introduction: oxidant stress, aging and exercise. Med Sci Sports Exerc 25, 210-212.

[44] Karbowski M (2010) Mitochondria on guard: role of mitochondrial fusion and fission in the regulation of apoptosis. Adv Exp Med Biol 687, 131-42. 
[45] Vissing J, Haller R G (2012) Mechanisms of exertional fatigue in muscle glycogenoses. Neuromusc Disord 22, 168-71.

[46] Ferreira A M D, Ribeiro B G, Soares E A (2001) Consumption of carbohydrates and lipids in ultra-endurance exercise performance. Rev Bras Med Esp 7(2), 67-74.

[47] Federico A, Cardaioli E, Da Pozzo P, Formichi P, Gallus G N, Radi E (2012) Mitochondria, oxidative stress and neuro degeneration. J of the Neuro Sci 322, 254-262.

[48] Sanchez G M, Hernandez R D, Garrido G G, Garcia M G, Rivera D G, Betancourt E P, Nunes-Selles A J (2003) Mitos y Realidades de la terapia antioxidante. Vimang: Nuevo Producto Natural Antioxidante. Cen of Pharmac Chem: Havana.

[49] Silva W J M, Ferrari C K B (2011) Mitochondrial metabolismo, free radical and aging. Rev Bras Geriatr Gerontol. 14 (3)

[50] Franco R L (2009) Expressão tumoral da glutationa S-transferase Pi e sobrevida global e livre de doença em mulheres com carcinoma de mama. Rev Bras Ginecol Obstet 31(2), 102-102.

[51] Kang D H, Há S K (2014) Uric Acid Puzzle: Dual Role as Anti-oxidantand Pro-oxidant. Electrolyte Blood Press 12(1), 1-6.

[52] Sitar M E, Aydin S, Cakatay U (2013) Human serum albumin and its relation with oxidative stress. Clin Lab 59(9-10), 945-52.

[53] Bertaggia E, Scabia G, Dalise S, Lo Verso F, Santini F, Vitti P, Chisari G, Sandri M, Maffei M (2014) Haptoglobin is required to prevent oxidative stress and muscle atrophy. PLoS One 9(6), e100745.

[54] Barnard M L, Muller-Eberhard U, Turrens J F (1993) Protective role of hemopexin on heme-dependent lung oxidative stress. Biochem Biophys Res Commun 192(1), 82-7.

[55] Biliet L, Doaty S, Katz J D, Velasquez M T (2014) Review of hyperuricemia as new marker for metabolic syndrome. ISRN Rheumatol. eCollection 2014.

[56] Constantine M M (2014) Physiologic and pharmacokinetic changes in pregnancy. Front Pharmacol 3(5), 65.

[57] Gundogdu E, Yurdasiper A (2014) Drug transport mechanism of oral antidiabetic nanomedicines Int $\mathrm{J}$ Endocrinol Metab $12(1), 8984$.

[58] Shahid M, Pourrut B, Dumat C, Nadeem M, Aslam M, Pinelli E (2014) Heavy-metal-induced reactive oxygen species: phytotoxicity and physicochemical changes in plants. Rev Environ Contam Toxicol 232, 1-44.

[59] Kontoghiorghe C N, Kolnagou A, Kontoghiorges G J (2013) Potential clinical applications of chelating drugs in diseases targeting transferrin-bound iron and other metals. Expert Opin Investig Drugs 22(5), 591-618.

[60] Kruzel M L, Actor J K, Zimecki M, Wise J, Płoszaj P, Mirza S, Kruzel M, Hwang S A, Ba X, Boldogh I (2013) Novel recombinant human lactoferrin: differential activation of oxidative stress related gene expression. J Biotechnol 168(4), 666-75.

[61] Iwanaga S, Sakano N, Taketa K, Takahashi N, Wang D H, Takahashi H, Kubo M, Miyatake N, Ogino K (2014) Comparison of serum ferritin and oxidative stress biomarkers between Japanese workers with and without metabolic syndrome. Obes Res Clin Pract 8(3), 201-98.
[62] Turgut A, Özler A, Görük N Y, Tunc S Y, Evliyaoglu O, Gül T (2013) Copper, ceruloplasmin and oxidative stress in patients with advanced-stage endometriosis. Eur Rev Med Pharmacol Sci. 17(11), 1472-8.

[63] Bryer S C, Goldfarb A H (2006) Effect of high dose vitamin C supplementation on muscle soreness, damage, function, and oxidative stress to eccentric exercise. Int J Sport Nutr Exerc Metab 16(3), 270-80.

[64] Rizvi S, Raza S T, Ahmed F, Ahmad A, Abbas S, Mahdi F (2014) The role of vitamin e in human health and some diseases. Sultan Qaboos Univ Med J 14(2), 157-65.

[65] Molnar J A, Underdown M J, Clark W A (2014) Nutrition and Chronic Wounds. Adv Wound Care (New Rochelle) 3(11), 663-681.

[66] Goufo P, Trindade H (2014) Rice antioxidants: phenolic acids, flavonoids, anthocyanins, proanthocyanidins, tocopherols, tocotrienols, $\gamma$-oryzanol, and phytic acid. Food Sci Nutr. 2(2), 75-104.

[67] Carocho M, Ferreira I C (2013) A review on antioxidants, prooxidants and related controversy: natural and synthetic compounds, screening and analysis methodologies and future perspectives. Food Chem Toxicol. 51, 15-25.

[68] Steckert A V, Castro A A, Quevedo J, Dal-Pizzol F (2014) Sepsis in the central nervous system and antioxidant strategies with $\mathrm{N}$-acetylcysteine, vitamins and statins. Curr Neurovasc Res 11(1), 83-90.

[69] Garrido-Maraver J, Cordero M D, Oropesa-Avila M, Veja A F, Mata M, Pavon A D, Alcocer-Gomez E, Calero C P, Paz M V, Alanis M, Lavera I, Cotan D, Sanchez-Alcazar J A (2014) Clinical applications of coenzyme Q10. Front Biosci Landmark Ed. 1(19), 619-33.

[70] Kumar S, Pandey A K (2013) Chemistry and biological activities of flavonoids: an overview. Scient Wor J 162750.

[71] Rodrigo R, Fernández-Gajardo R, Gutiérrez R, Matamala J M, Carrasco R, Miranda-Merchak A, Feuerhake W (20130) Oxidative stress and pathophysiology of ischemic stroke: novel therapeutic opportunities. CNS Neurol Disord Drug Targ 12(5), 698-714.

[72] Fu H, Li G, Liu C, Li J, Wang X, Cheng L, Liu T (2014) Probucol Prevents Atrial Remodeling by Inhibiting Oxidative Stress and TNF- $\alpha / \mathrm{NF}-\kappa \mathrm{B} / \mathrm{TGF}-\beta$ Signal Transduction Pathway in Alloxan-induced Diabetic Rabbits. J Cardiovasc Electrophysiol. doi: 10.1111/jce.12540.

[73] Rochette L, Zeller M, Cottin Y, Vergely C (2014) Diabetes, oxidative stress and therapeutic strategies. Biochim Biophys Acta 1840 (9), 2709-29.

[74] Ramel F, Mialoundama A S, Havaux M (2013) Nonenzymic carotenoid oxidation and photooxidative stress signalling in plants. J Exp Bot 64 (3), 799-805.

[75] Houston M C (2010) The role of cellular micronutrient analysis, nutraceuticals, vitamins, antioxidants and minerals in the prevention and treatment of hypertension and cardiovascular disease. Ther Adv Cardiovasc Dis. 4 (3), 165-83.

[76] Cordova A, Navas F J (2000) Os radicais livres e o dano produzido pelo exercício: papel dos antioxidantes. Rev Bras Med Esp 6 (5), 204-208. 
[77] Zoopi C C, Neto J A, Catanho F O, Goulart L F, Motta E, Moura N, Macedo D V (2003) Alterações em biomarcadores de estresse oxidativo, defesa antioxidante e lesão muscular em jogadores de futebol durante uma temporada competitiva. Rev Paul Educ Fís, (17), 119-130.

[78] Nascimento E B, Leite R D, Prestes J (2011) Cancer: Benefits of resistance and aerobic training. R. da Educ Fís/UEM 22 (4), 651-658.

[79] König D, Wagner K H, Elmadfa I, Berg A (2001) Exercise and oxidative stress: significance of antioxidants with reference to inflammatory, muscular, and systemic stress. Exerc Immunol $\operatorname{Rev}(7), 108-33$.

[80] Tiidus P M (1998) Radical species in inflammation and overtraining. Can J Physiol Pharmacol 76 (5), 533-8.

[81] Perry J D (1992) Exercise, injury and chronic inflammatory lesions. Br Med Bull. 48 (3), 668-82.

[82] Angeli A, Minetto M, Dovio A, Paccotti P (2004) The overtraining syndrome in athletes: a stress-related disorder. J Endocrinol Invest. 27 (6), 603-12.

[83] Walsh N P, Gleeson M, Shephard R J, Gleeson M, Woods J A, Bishop N C, Fleshner M, Green C, Pedersen B K, Goetz L H, Rogers C J, Northoff H, Abbasi A, Simon P (2011) Position Statement Part one: Immune function and exercise. EIR (17) position statement part I.

[84] Morton A R, Keast D (1991) Overtraining in athletes. Sports Med. 12(1), 32-65.

[85] Faria I E (1992) Energy expenditure, aerodynamics and medical problems in cycling. Sports Med 14(1), 43-63.
[86] Fry A C, Kraemer W J (1997) Resistance exercise overtraining and overreaching. Neuroendocrine responses. Sports Med. 23(2), 106-29.

[87] Hadden J W (2003) Immunodeficiency and cancer: prospects for correction. Inter Immunophar (3), 1061-1071.

[88] Barp C G, Almeida D J, Freitas G B L (2014) Breast Cancer and Postmenopausal Obesity: The Risk Factors in this Relationship". Can Res J 2(1), 9-14.

[89] Sikora J P, Chlebna-Sokol P, Andrzejewska E, Chrul S (2008) Clinical evaluation of proinflammatory cytokine inhibitors (s TNF r I, s TNF r II, IL-1ra), anti-inflammatory, cytokines (IL-10, IL-13) and activation of neutrophils after burn-induced inflammation. Clin Immul (68), 145-152.

[90] Teramoto M, Bungum T J (2010) Mortality and Longevity of elite athletes. J of Sci and Med in Sport (13), 410-416.

[91] Smith L L (2003) Overtraining, excessive exercise, and altered immunity: is this a $\mathrm{T}$ helper-1 versus $\mathrm{T}$ helper-2 lymphocyte response?. Sports Med (33), 347-64.

[92] Bassini A, Cameron L C (2014) Sportomics: Building a new concept in metabolic studies and exercise science. Bioch and Biophysl Res Commun (445), 708-716.

[93] Sormunen J, Backmand H M, Sarna S, Kujala U M, Kaprio J, Dyba T, Pukkala E (2014) Lifetime physical activity and cancer incidence - A cohort study of male former elite athletes in Finland. J of Sci and Med in Sport (17), 479-484. 